\title{
A Hierarchical Approach for the Sustainability of Residential Building Regeneration
}

\author{
Guopeng Li, Jing Zhou, Lingxi Wang \\ School of Architecture and Fine Arts, Dalian University of Technology, Dalian, China \\ Email: liguopeng@dlut.edu.cn
}

How to cite this paper: Li, G.P., Zhou, J. and Wang, L.X. (2019) A Hierarchical Approach for the Sustainability of Residential Building Regeneration. Open Journal of Social Sciences, 7, 269-280. https://doi.org/10.4236/jss.2019.710022

Received: September 11, 2019

Accepted: October 20, 2019

Published: October 23, 2019

Copyright $\odot 2019$ by author(s) and Scientific Research Publishing Inc. This work is licensed under the Creative Commons Attribution International License (CC BY 4.0).

http://creativecommons.org/licenses/by/4.0/

\section{cc) (i) Open Access}

\begin{abstract}
After the enormous advancement of urbanization from the past 30 years, the functional and environmental quality of a large number of existing residential buildings poses a serious challenge to the sustainability of urban living. It is of great significance to retrofit the existing residential buildings in order to improve the living quality. However, due to complexity of residential issues, retrofitting of existing residential areas is not only some simple revising and reconstructing projects of residential buildings and environments, but also multidimensional and interdisciplinary theoretic research and engineering practices. Thus, this research study, taking the residential buildings built between 1980 and 2000 in Northeast China as the research objects, attempts to systematically put forward a regenerative method that offers an overall sustainable retrofitting plan of residential buildings. This paper, starting from investigating the complex issues of existing residential buildings, summarises the contradictions between the requirements from residents and current retrofitting approaches. Then, to resolve the contradictions, hierarchical theories, such as Open Building and Shearing Layers, are introduced based on documentary analysis and case studies. And finally, a sustainable regenerative design approach is proposed to hierarchically control the qualitative and quantitative retrofitting of existing residential buildings. The findings of this research will extend and improve the role of occupants' participation in the retrofitting of residential buildings. It can also provide methods for the achievement of the long-term effectiveness and environmental sustainability.
\end{abstract}

\section{Keywords}

Hierarchical Theory, Open Building, Residential Building, Retrofitting Approach

\section{Research Background and the Issues}

With the rapid advancement of urbanization in the past 30 years, the function 


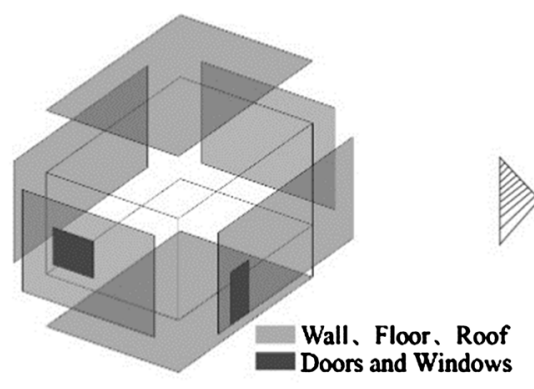

The stratification of the residential unit

and environmental quality of a large number of existing residential areas have restricted the improvement of living standards [1]. Although the functional quality of these residential areas has been out-of-date, the structural design is far from reaching its service life, which poses a serious challenge to the sustainable regeneration of urban residential areas. Therefore, it is imperative to retrofit existing residential areas. However, due to complexity of residential issues, retrofitting of existing residential areas is not only some simple revising and reconstructing projects of residential buildings and environments, but also multidimensional and interdisciplinary theoretic research and engineering practices. First of all, the existing residential environment is chaotic, with no hierarchy and no classification [2], for example, green space, parking space, residential activity places and other functions are missing or the division among them is unclear. Second, the residential building itself had low design standards at the time, low construction levels and aging components, which caused thermal insulation and other residential functions could not meet residents' comfort requirements at the current stage [3]. At the same time, the interior space has low adaptability [4]: the space is designed monotonous and formalized, and with the economic development and the family structure changes, it is increasingly unable to meet people's diversified living requirements.

In the existing retrofitting methods in China, there is no complete theoretical and practical guidance to solve the problems of low quality of existing residential environment, degraded residential building performance and low interior space adaptability. The existing research is mainly focused on the transformation of single indicators, such as thermal insulation and structural reinforcement. The current retrofitting methods in China mainly consist of the followings [5] [6] [7]:

1) Retrofitting method based on energy saving reconstruction of residential buildings, which only aims at the residential building level in accordance with the mandatory standards for energy saving of residential buildings, including envelope structure (Figure 1, taking the retrofitting of enclosure structure as an example), heating system, heating and cooling system, lighting equipment, and hot water supply facilities. It is applied to satisfy a basic function of residents'

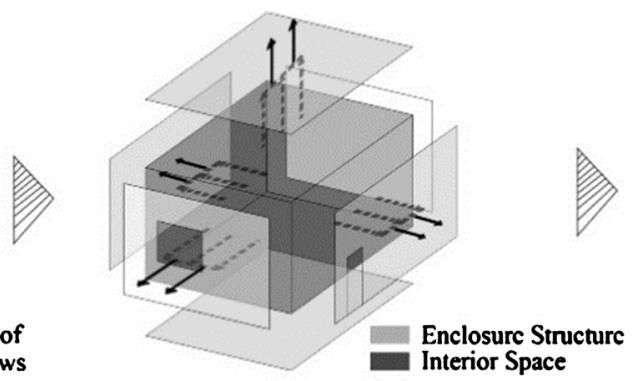

Heat loss of existing buildings

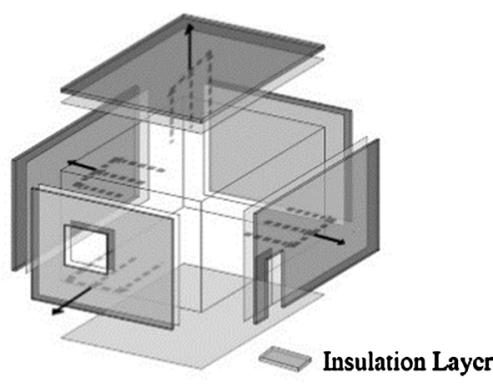

Heat loss after renovation

Figure 1. The retrofitting method of energy saving, the retrofitting of enclosure structure is the most effective method for energy saving, as energy consumption of building envelope accounts for about $50 \%-60 \%$ of the total energy consumption. 
needs quickly under limited economic conditions.

2) Retrofitting method based on the comprehensive functional regeneration of residential areas, which is the most common method of retrofitting residential areas in China at present (Figure 2). Although this method has been expanded to cover the residential related functional retrofitting of the existing buildings, but in essence, it is still based on energy-saving retrofitting with additional values, such as, on the building level, design for ageing related retrofitting measures are adopted, including adding elevators to multi-story buildings in residential buildings; on the environmental level of residential areas, the retrofitting focuses on the regeneration from landscape to individual facilities, and effectively consider the needs of the elderly in different age groups. In addition to the expansion of the retrofitting scope compared to energy-saving retrofitting pattern, the essence of the comprehensive regeneration methods has not changed, it only proposes single solution to individual problem and cannot solve multiple and complex residential issues.

Among a series of retrofitting methods that have emerged so far, it can be seen that there are fuzzy hierarchical directions indicating residential environment, residential buildings and interior space, but there is no clear levels and boundaries. The contradictions between the requirements from residents and current retrofitting approaches leaded by government and constructional companies are the actual issues of retrofitting existing residential buildings, which are multiple and complex. In order to solve the issues, the exploration of the effective method of residential area retrofitting should systematically put forward some hierarchical and periodic retrofitting design patterns. This research study based on the three levels of residential environment, residential building and interior space, summarizes the suitable retrofitting design pattern of the existing residential areas through literature review and case study.

\section{Hierarchical Theories and Case Study}

\subsection{Open Building on Hierarchy Control}

In the stock age of residential areas, people gradually realize that the waste of resources and various social and environmental problems are caused by large demolition and construction. The simplest and direct solution began to be questioned and criticized by people from all walks of life. At the same time, in the

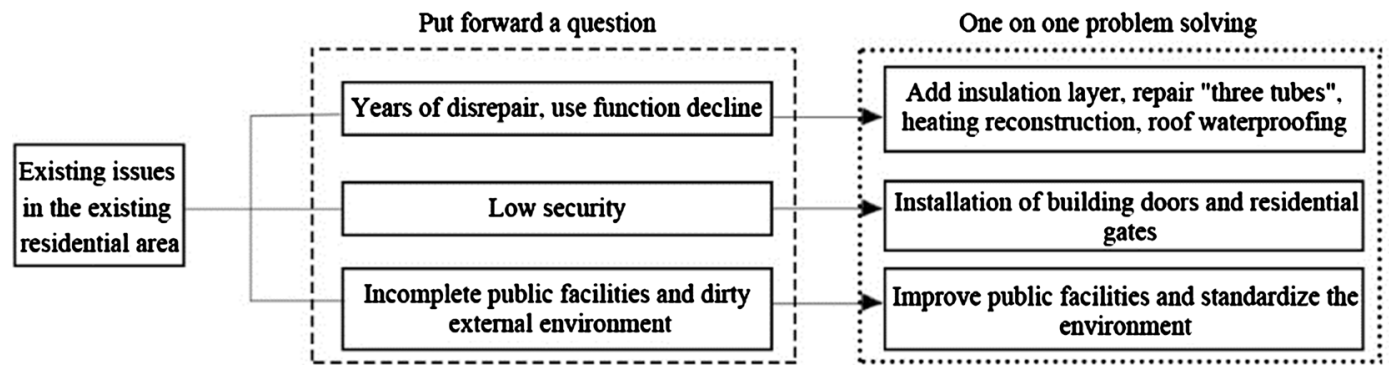

Figure 2. The retrofitting method based on the comprehensive transformation of residential function. 
three different levels of residential environment, residential building and interior space, there have been many beneficial explorations at home and abroad in recent years for the retrofitting of existing residential areas. Among them, the most important method/theory in the relevant theoretical explorations is Open Building.

One of the features of the Open Building concept is the "Hierarchy and Levels of Control". Tissue, support and infill are the three basic levels in Open Building. Habraken [8], in talking about a building consisting of material components and spatial components, argues that every building can be regarded as a system of components, ordered according to certain rules. These components could be material ones, walls, floors and roofs, etc. Alternatively, a building can be considered as a system of spaces, a system in which the spaces are the components, and the relationships between those spaces conform to certain rules. Lin and Wang [9], based on the Open Building concept, developed and specified the levels of control into seven environmental levels: region level, city level, district level, block level, building level, room level, and body space level. They also distinguish the material components and the spaces determined by the material components. Firstly, those environment levels, according to hierarchy, distinguish the material components of the built environment into seven levels: highway, artery, street, structure, partition, furniture, and utensil. The higher level of the two adjacent material components is the Support, whereas at the lower level is the Infill of Open Building. The higher the level positions, the lower the freedom it has due to the greater range it affects, and vice versa. Then, two adjacent levels of material elements define one type of space, so that there are seven levels of spatial scale: region, city, district, block, building, room, and body space (Figure 3).

Placing emphasis on buildings, the hierarchy between building level and room

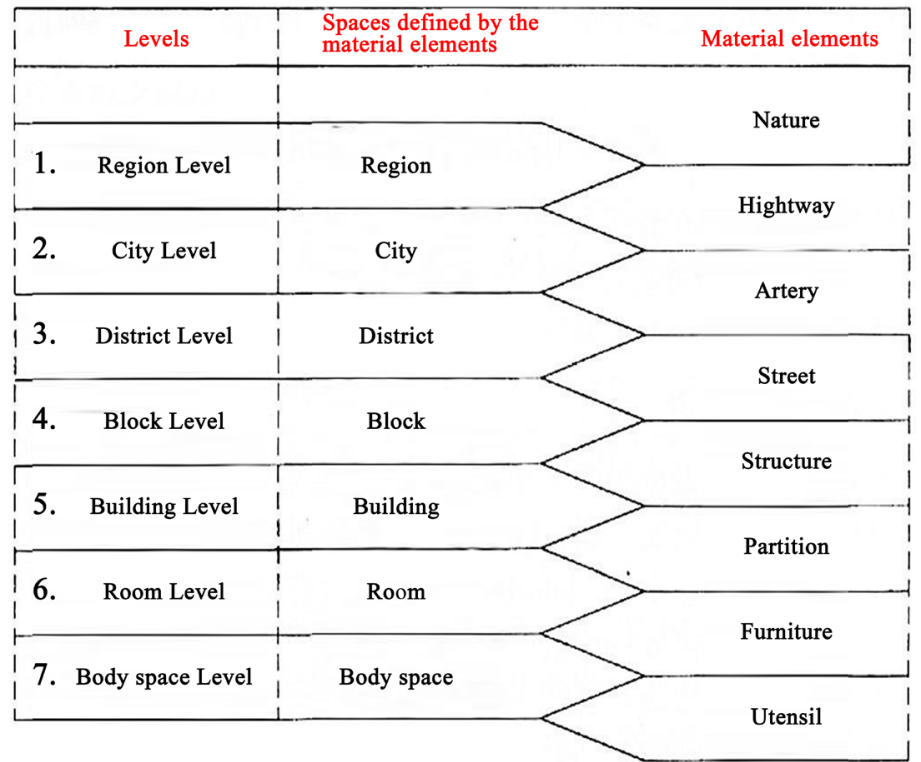

Figure 3. Levels of control and their relation to components ([9] p. 118). 
level has been shown, and comprises material components (structure, partition, and furniture) and spaces (building and rooms) (Figure 4).

\subsection{Hierarchical Theories about Layers}

From Francis Duffy's four layers [10], via Brand's six layers [11], to Adaptable Futures' eight layers, the layering idea has been expressed as showing that buildings need to accommodate different cycles of change for them to last well and improve over time.

Francis Duffy developed a categorisation in the office building sector based on the description and measurement of buildings in terms of time (Figure 5). His view was that an office building has three architectural layers, named Shell, Services, and Scenery, as well as the day-to-day changed non-architectural Set within the three architectural layers. Duffy believed that the Shell (structure and enclosing cladding) should last for the lifetime of a building.

- Shell: the structure and the enclosing cladding; it lasts the lifetime of the building, which is about 50 years in the UK;

- Services: the cabling, plumbing, air conditioning and elevators; they have to be replaced approximately every 15 years;

- Scenery: the layout of partitions and finishing; it changes every five to seven years;

- Set: the shifting of furniture and appliances; it interacts with the users and often changes daily.

Stewart Brand expanded Duffy's categorisation of an office building into a

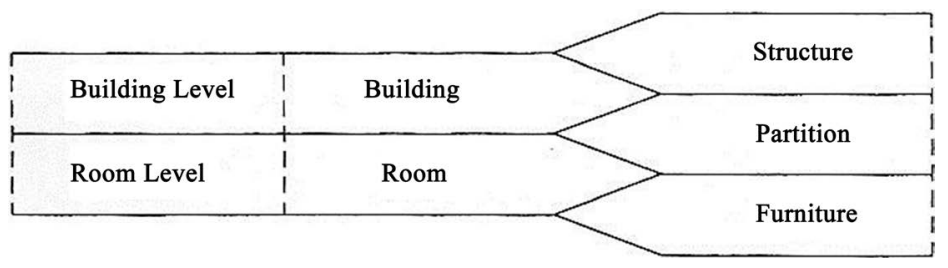

Figure 4. Levels and components in a building system ([9] p. 118).
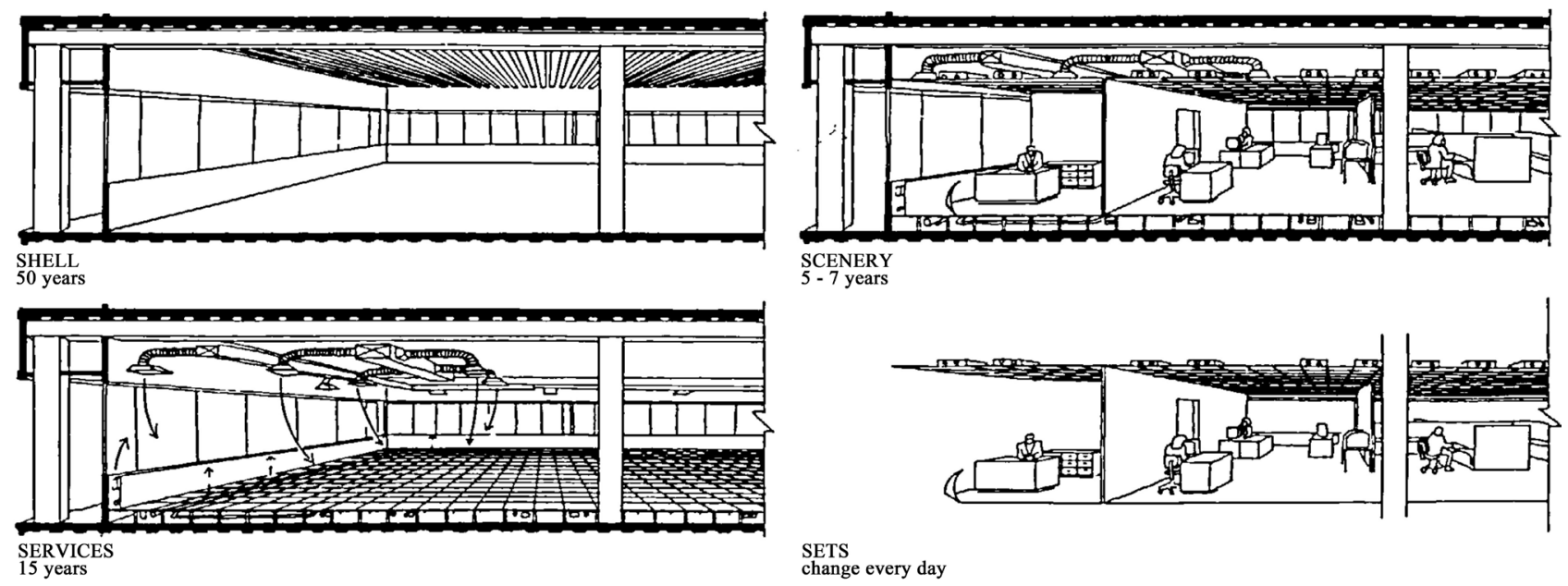

Figure 5. Duffy's shell, services, scenery and sets life cycles ([10] p. 17). 
slightly revised, general purpose, six layers of change (Figure 6) to precisely follow the design and construction and show the recycling of buildings. Both Brand and Duffy agreed that the site is eternal, but Brand emphasised that "These (structures) are the building".

- Site: the geographical setting, the urban location and the legally defined lot-the boundaries and context outlast generations of ephemeral buildings;

- Structure: the foundation and load bearing elements whose life ranges from 30 to 300 years;

- Skin: the exterior surfaces that change about every 20 years;

- Services: the working guts of a building and moving parts like elevators and escalators that need to be replaced every seven to 15 years;

- Space plan: the interior layout showing the arrangement of walls, ceilings, floors and doors. It lasts from three (commercial space) to 30 (domestic) years;

- Stuff: the non-architectural components (furniture and belongings). All these reform at daily to monthly intervals.

The Adaptable Futures' layers, using Brand's original diagram as a starting point, show that buildings are made up of a set of "shearing" layers that change at different rates (Figure 7). It includes a social layer to include the humans in and around the building. It also adds a set of surroundings layer, which encompasses many of the neighbouring locational factors that also play a role in how a building and its constituent parts will change over time.

These layers of different lift-span, mainly focusing on physical/material attributes, are more specific when compared to the levels of Open Building, in particular in the services area. Services are defined by Duffy as the cabling, plumbing, air conditioning and elevators, and which have to be replaced approximately every 15 years. In Open Building, it is part of either Support or Infill, whereas in the layers of buildings, services are picked up to compose one layer in the system.

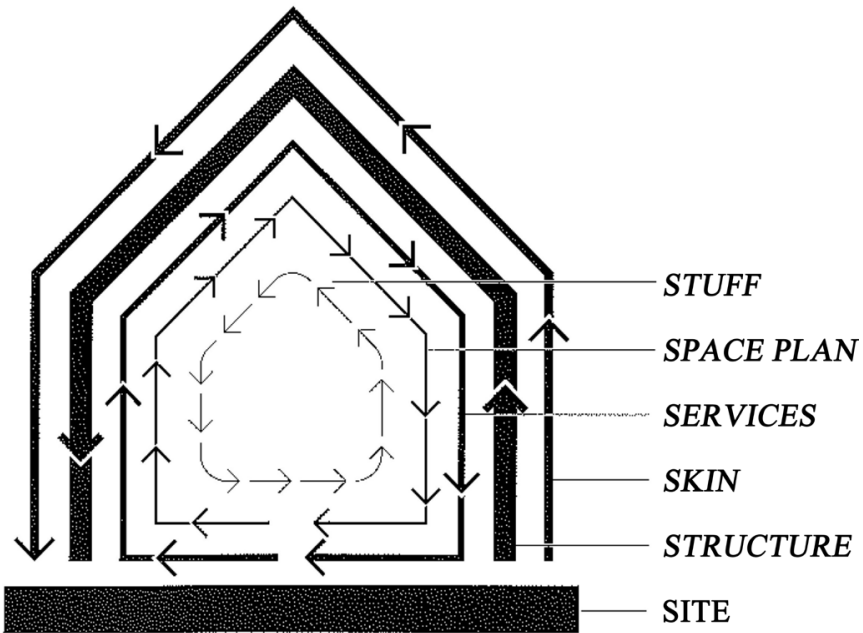

Figure 6. Brand's shearing layers of change ([11] p. 13). 


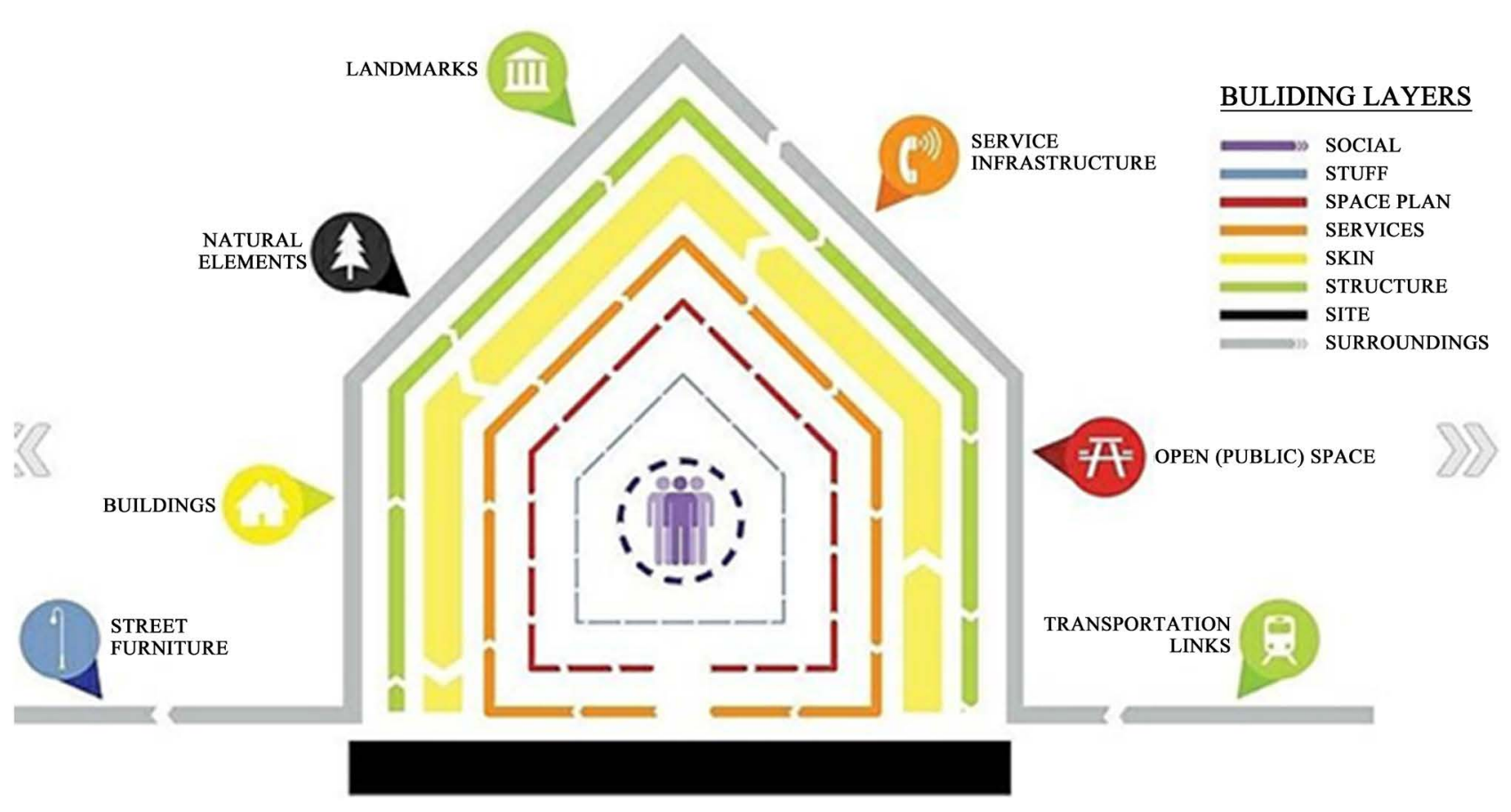

Figure 7. Adaptable Futures' building layers.

\section{3. "Polyvalence" and "Frame"}

Criticising the neutrality and uncertainty of an open-ended solution to "Open Building", Hertzberger [12] introduced a new concept of permanence called "Polyvalence": "Polyvalence" is considered to be the only constructive approach to a situation that is subject to change, which is a static form of changefulness. Thus, "Polyvalence" is a form that can be put to different uses without having to undergo changes itself. Bernard Leupen [13] agrees with Hertzberger's opinion that the ability to change is by virtue of the permanent. He explains through the following example how the permanent frees the temporary: a non-load-bearing partition wall can be placed at will thanks to the presence of the structure, the load-bearing part of the building; it is not the wall itself but the structure that allows the wall to be freely placed by relieving the wall of its load-bearing capacity. Leupen, on the understanding of the permanent, develops his method of "Frame": frame, in this sense, is the permanent aspect and it can be distinguished into a system of five layers: Structure, Skin, Scenery, Services and Access (Figure 8).

- Structure, which transmits the loads to the ground, consists of columns, beams, load-bearing walls, trusses and structural floors;

- Skin, which separates inside from outside and, at the same time, presents the building to the outside world, consists of cladding for façade, base and roof;

- Scenery, which orders and bounds the space, consists of internal cladding, internal doors and walls, finish of floors, walls and ceilings;

- Services, which regulate the supply and discharge of water, energy, information and air, include the necessary appliances and the spaces primed to accept these, such as pipes and cables; 

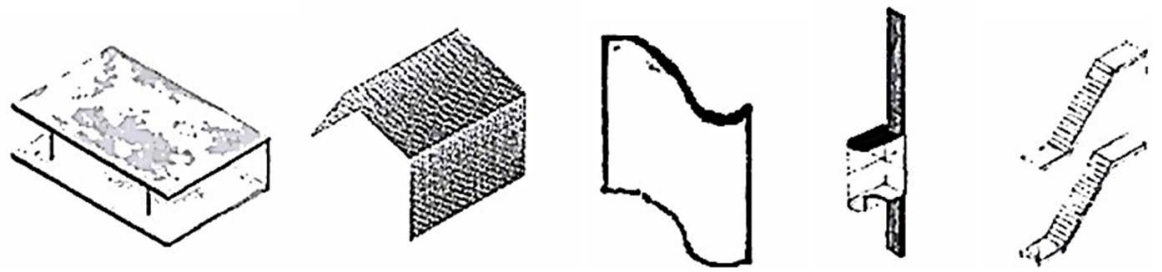

Figure 8. Five layers of frame: (from left to right) Structure, Skin, Scenery, Services, and Access ([13] p. 32).

- Access takes care of the accessibility of the spaces and/or the individual homes.

In summary, with the contributions of Habraken and some other researchers, hierarchy control has become a well-established design methodology. Projects have been designed and built in accordance with the design principles of hierarchical theories in different countries, which shows that with careful planning of housing processes, agreements among a variety of parties, and good design skills, architects may exemplify the impact of innovation on the reduction of monotony in conventional mass housing and restoration of individuality in design.

\subsection{Case Studies of Residential Retrofitting}

Case study 1: The retrofit of existing dwellings in Wahlberg, Netherlands [14] [15]. The main purpose of this case study is using the Open Building theory to improve the quality of residential areas on three levels, consisting of the tissue level (residential environment), the support level (building structure) and the infill level (interior space) (Figure 9 shows the analytical details on three levels and indicates the method used on each level). There are two retrofitting measures on each level, changing the control mode and retrofitting the structure itself. At the tissue level, small houses were built to improve the relationship with the streets, and old garages were removed. At the support level, add the elevator, expand the balcony, improve the insulation performance of the enclosure structure, etc. At the infill level, some or all of them were renovated according to the household needs and funding status. The project improved the quality of the residential area as a whole.

Case study 2: An Huili Nursing Care Centre in Asian Sports Village, Beijing [16] [17] [18]. Under the guidance of the Open Building theory, the practice of the nursing care centre in Asian Sports Village was the "Suitable for Aging" renovation in the existing residential area, and the integrated service building was transformed into a comprehensive nursing care centre. The transformation was carried out on the two levels of residential building and interior space (Figure 10 presents a clear distinction between physical and functional retrofitting carried out on building level and interior space level), the physical performance of the building was strengthened, and the interior space quality and spatial sustainability were enhanced by the industrialization of interior decoration. 

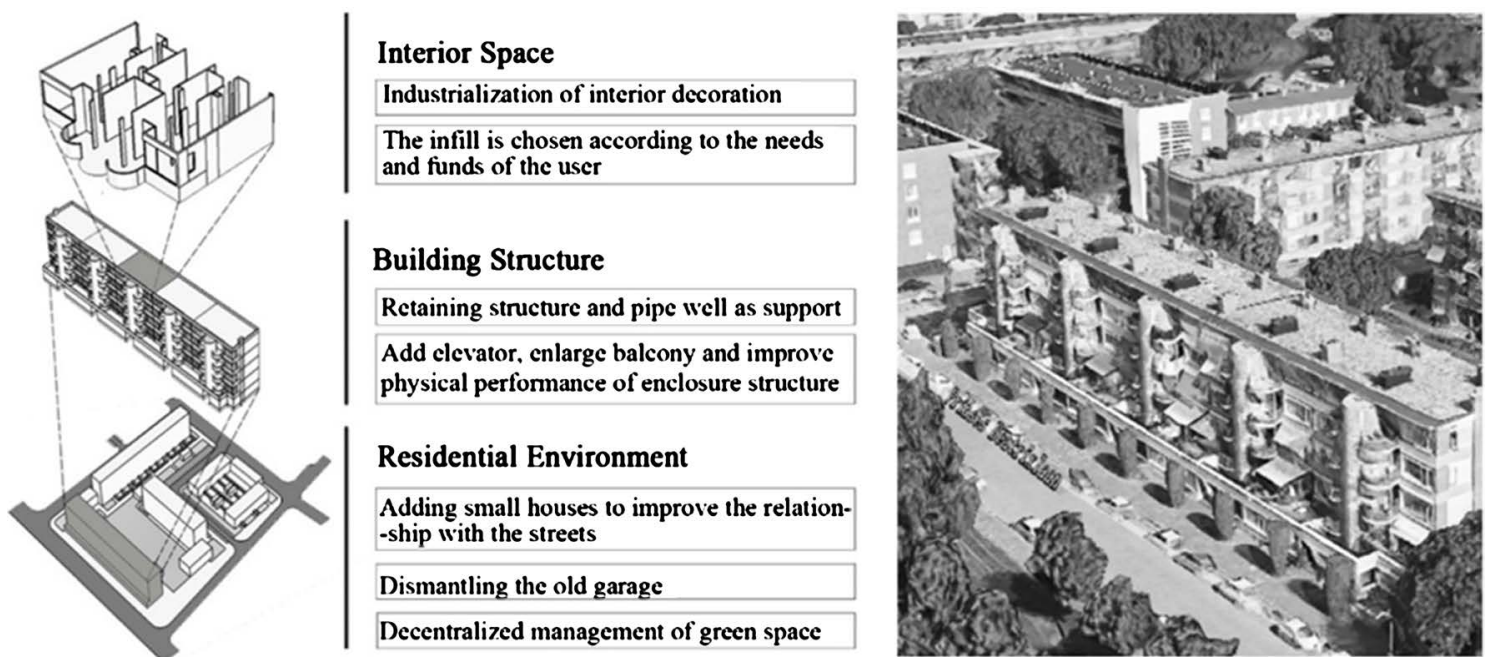

Figure 9. The hierarchical control of the retrofitting of Wahlberg's residential area in Netherlands.
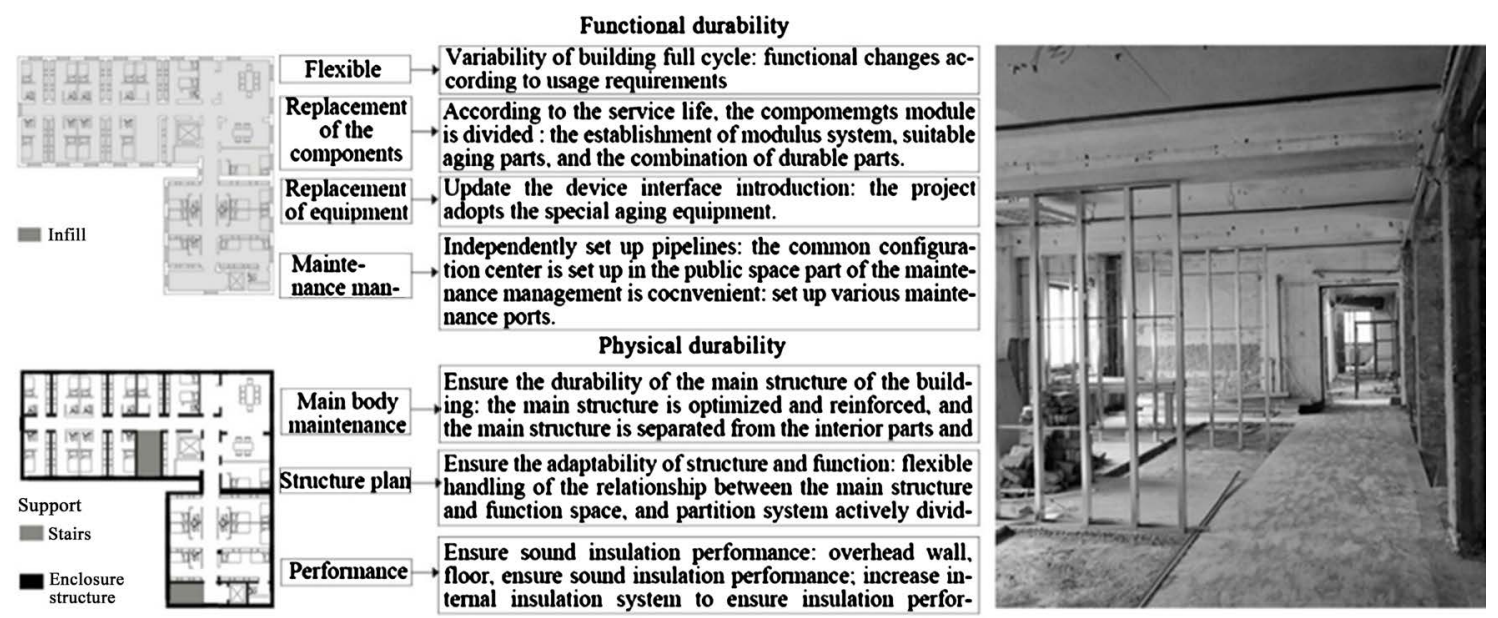

Figure 10. A Huili Nursing Care Centre in Asian Sports Village, Beijing.

\section{Sustainable Regenerative Design Approach of Existing Residential Areas}

Aiming at multiple and complex residential issues, the existing residential area is divided into three levels of residential environment, residential building and interior space by using the outer enclosure structure of building and the wall between the residential unit and the other units. In this way, the sustainable renovation design pattern of the existing residential area is explored on the basis of hierarchy.

- Investigation of conservation capacity in the early stage: The research on the capacity of each level of the existing residential area is carried out. The elements within each level in the residential areas are compared with the new residential standards (regulations), the missing or redundant functional elements of the residential area are obtained. Combining the limited space of the residential area and the limitation of the existing structure, the redundant elements are eliminated. The missing elements are to judge whether the level 
has the ability to make up the missing elements through a simple supplement. If the level does not have the ability to accommodate the missing elements, it is necessary to integrate the existing space through spatial complication to improve the utilization ratio of space. If there is such a capacity, then necessary maintenance or renovation or new construction should be carried out to accommodate the missing functional elements. Maintenance and retrofitting, compared with new construction, occur at all levels, and each level is restricted by existing interfaces. In short, it is to solve the problem of renovation design within all levels of existing residential areas.

- Encouraging residents to participate: It is particularly important to encourage the residents to participate in the regenerative design of the existing residential areas, but how to balance the macro control from the government and the requirements from the housing market, that is, how to balance the private (autonomy) and the public (communal governance), it is necessary to confirm the design of the elements in the hierarchy through market prediction, so as to determine the reasonable range of public and private information that the market, the government and the residents can accept.

- Associating regeneration design with adaptability: Meanwhile, the renovation design of existing residential areas is related to adaptability, and adaptability is achieved by industrialization of interior and exterior components. Industrialization provides technical support for the self-improvement of the residents on the interior space level. In the whole life cycle of the dwelling, it is possible for residents to maintain and retrofit the interior space by themselves.

- Determine the order of transformation according to the urgency of demand: In the time dimension, the renovation sequence of residential areas should be determined according to the urgency of the demand, first to solve the most urgent needs, in order to meet the basic requirements of the residents as the starting point, and then gradually improve the quality of the residential area.

\section{Conclusions}

In view of the multiple and complex situation of existing residential areas in China, a sustainable retrofitting design pattern is proposed by literature research and case analysis. The existing residential areas are divided into "three levels"-residential environment, residential buildings and interior spaces, "two interfaces"- the external maintenance structure of residential building and the wall between units and the other units. Through the investigation of the capacity of each level of the existing residential area, the missing or redundant elements in the hierarchy are determined, if the capacity is insufficient, it will integrate through the combination of space, on the contrary, it will directly maintain, retrofit or build new residential areas. At the same time, according to the urgency of the residents' demand, the order of retrofit in the time dimension should be considered. Also, encouraging residents to participate will improve adaptability 
and sustainability with the help of industrialization of interiors and components.

The sustainable retrofitting design pattern can provide new ideas for regenerating a large number of existing residential buildings in China, and expand and improve the role and scientificity of architectural design in the retrofitting of existing residential buildings. However, the industrial development of the interior decoration and components is still at an initial stage. And in practice, limited to the original structure of existing residential areas, higher standards and more stringent requirements are desired for the flexibility and adaptability of the industrialization of the constructional components.

\section{Acknowledgements}

The authors would like to acknowledge the support by the National Natural Science Foundation of China, Grant No. 51638003 and 51808093, and Natural Science Foundation of Liaoning, Grant No. 20180550269.

\section{Conflicts of Interest}

The authors declare no conflicts of interest regarding the publication of this paper.

\section{References}

[1] Fan, Y., Li, Z. and Dong, L. (2018) The Environment Quality Connotation and Regeneration Mode for the Existing Community Residential Buildings in China. New Architecture, 2, 46-49.

[2] Suo, J., Zhou, Q. and Fan, Y. (2018) Thoughts on the Practice and Existing Problems of Urban Housing Quality Improvement in China. Journal of Human Settlements in West China, 33, 1-5.

[3] Li, G., Xu, Y. and Fan, Y. (2018) A Design Approach towards the Sustainable Retrofitting and Energy-efficiency Optimization of Residential Buildings. The 9 th Edition of the International SOLARIS Conference, Chengdu, 26-27.

[4] Li, G., Fan, Y. and Li, Z. (2015) Open Design for Adaptability in Chinese Public Housing. The Future of Open Building Conference, Zurich, 9-11.

[5] Li, H. and Wang, Q. (2011) Integrated Retrofitting of Existing Buildings, Case Studies. China Architecture and Building Press, Beijing.

[6] Jiang, Y. (2015) Retrofitting of Existing Buildings Yearbook 2014. China Architecture and Building Press, Beijing, 338-348.

[7] Dong, W. and Wang, Z. (2017) A Comparative Study on the Public Participation of Government Leading and Community Leading Urban Regeneration-A Case Study of Beijing Old City Conserve Regeneration Practice. Journal of Human Settlements in West China, 32, 19-25.

[8] Habraken, N.J., Boekholt, J.T., et al. (1976) Variations: The Systematic Design of Supports. Laboratory of Architecture and Planning at MIT, Cambridge, MA.

[9] Lin, L.C. and Wang, M.H. (2000) Measuring the Openness of Component Interface for Residential Building. In: Wang, M.H., Ed., Selected Papers on Open Building: Towards a User Friendly Building Industry, Taipei, 111-143.

[10] Duffy, F. (1990) Measuring Building Performance. Facilities, 8, 17-20. 
https://doi.org/10.1108/EUM0000000002112

[11] Brand, S. (1995) How Buildings Learn: What Happens after They're Built. Penguin Books, New York.

[12] Hertzberger, H. (1991) Lessons for Students in Architecture [translated from the Dutch by Ina Rike]. Uitgeverij 010 Publishers, Rotterdam.

[13] Leupen, B. (2006) Frame and Generic Space. Uitgeverij 010 Publishers, Rotterdam.

[14] Miao, Q., Zhou, J. and Chen, J. (2016) The Design and Features of European Housing on the basis of Open Building Theory. Housing Industry, 4, 18-25.

[15] Dekker, K. (1996) Consumer Oriented Renovation of Apartments. Voorburg, the Netherlands.

https://repository.tudelft.nl/view/tno/uuid:70a73529-b786-4a7a-8e4e-05f1bebd095e

[16] Liu, D., Liu, R. and Qin, S. (2017) SI Construction Method and Infill Industrialized Transformation of Renewal of Existing Buildings: A Case Study of Design and Construction of Old-Age Caring Facilities in Anhuili, in Beijing. Urbanism and Architecture, 13, 17-22.

[17] Liu, D., Shao, L., Jiang, Y. and Fan, J. (2019) Shokai Anhuili Elderly Caring Facility, Beijing, China, 2017. World Architecture, 1, 159-162.

[18] Liu, D., Qin, S., Fan, J. and Wu, Z. (2017) A Study on Composite Care Facilities for the Elderly Based on Urban Renewal of Residential Areas. Architectural Journal, 10, 23-30. 